\title{
2. Third actors initiating business relationships for a medical device start-up: effect on network embedding and venture creation processes
}

Tamara Oukes \& Ariane von Raesfeld on behalf of the PCDIAB consortium

\subsection{Introduction}

It is widely recognised that it is essential to the survival and growth of start-ups to initiate, develop and maintain business relationships (e.g. Aaboen, Dubois, \& Lind, 2011; La Rocca, Ford, \& Snehota, 2013). Only through establishing business relationships can start-ups embed themselves in the pre-existing developing, producing and using setting (Håkansson, Ford, Gadde, Snehota, \& Waluszewski, 2009). However, start-ups often experience difficulties in initiating the necessary business relationships (Prashantham \& Birkinshaw, 2008). To cope with this challenge, Oukes and Raesfeld (2014) found that a start-up used the mediating function of its partners to initiate new relationships. They showed that after it was made aware of, introduced to or referred to a potential partner by one of its existing partners; the start-up could mobilise valuable resources from new partners.

Other researchers (e.g. Aarikka-Stenroos, 2011; Aarikka-Stenroos \& Halinen, 2007; Kirkels \& Duysters, 2010; Yin, Wu, \& Tsai, 2012) have also highlighted the important role of 'third actors' in initiating relationships. Nevertheless, these studies focused on the perspective of the third actor - the one who connects-rather than the actors that are connected. Yet the connection function of a start-up itself is usually limited due to a lack of power, influence, information and control benefits, as well as the constraints on network activities with which it is confronted (Shipilov, Li, \& Greve, 2011; Yin et al., 2012). Nonetheless, the connection function of its partners can support the initiation of a start-up’s business relationships in two ways. First, third 
actors reduce the uncertainty associated with the competencies and resources of a start-up's potential partners by connecting complementary partners in a way that is beneficial to all parties (Howells, 2006). Secondly, a start-up can mitigate the possible detrimental effects of its limited network by relying on its partners to connect some of their existing relationships to the start-up (Holmen \& Pedersen, 2003).

In addition, research has shown that the initiation of business relationships will affect the extent to which the start-up embeds itself in the pre-existing network and develops its business (Lamine, Jack, Fayolle, \& Chabaud, 2015). For example, Mainela, Pernu, and Puhakka (2011) define four specific behaviours_internal problem-solving, external solution-creation, opportunity selling, and opportunity organising —as the primary drivers of the development of start-ups and embedding them in networks. Although these studies have given us a valuable understanding of the network embedding process and start-up business development, this type of study usually looks at the initiation of several dyads, that is the relation between two organisations (e.g. Aaboen et al., 2011; La Rocca et al., 2013), or the initiation of a portfolio, that is the relations of a single organisation (e.g. Anderson, Dodd, \& Jack, 2010; Huggins, Izushi, Prokop, \& Thompson, 2015; Mainela et al., 2011). However, relatively little research has investigated the effect of third actors on the network embeddedness and business creation processes.

In summary, only limited research has been undertaken into how third actors influence the process of start-up relationship initiation and how this in turn affects the process by which they embed themselves in the pre-existing network and develop their business. Therefore, our aim is to investigate how third actors influence a start-up's business relationship initiation and subsequent network embedding, as well as its business development. This research aim is 
addressed in a case study of a start-up. The company involved is developing a medical device for the treatment of persons with diabetes. In the medical device industry, innovation is located within networks in which universities, start-ups, established firms, venture capitalists and professional service firms collaborate. Especially in such a network-based structure, centrally positioned third actors can support the emergence of resource constellations and activity patterns between start-ups and other members of the network (Styhre \& Remneland-Wikhamn, 2015). This chapter starts by sketching a framework of the relevant theory. After that, the method used to address the research aim is briefly discussed. The Results and Discussion sections describe the findings of the case study, analysing the key findings in light of the theory. The chapter ends with our conclusion, discusses the limitations and avenues for future research.

\subsection{Theory}

\subsubsection{Third actors and a start-up's relationship initiation}

Edvardsson, Holmlund, and Strandvik (2008) showed that the process of relationship initiation consists of three statuses, with increasing likelihood that a business agreement will be achieved: (1) unrecognised, that is the parties do not know each other; (2) recognized, that is there is an awareness of the parties of mutual business opportunities; and (3) considered, that is companies negotiate the objective, scope and terms of the business relationship. The relationship initiation process ends and the relationship begins with the closing of a business agreement. Although the authors developed a conceptualisation of the dynamics in the business relationship initiation process, they did not consider the role and function of third actors in this process. Yet business relationships—especially those of start-ups—seldom start from direct approaches, such as cold 
calls, but often come about with the support of third actors, which introduce two or more matching business partners (Aarikka-Stenroos, 2009).

In particular, third actors are considered to have three functions and four roles in relationship initiation within the IMP tradition. Holmen and Pedersen (2003) discern three mediating functions of three actors: joining, relating and insulating. Joining enables direct coordination on some aspects between the firm of interest and the firm's counterparty. Relating facilitates coordination between the firm and a third party via the counterparty, with both parties having knowledge of each other. Insulating permits coordination between the firm and the third party without the parties having any knowledge of each other. In addition, Aarikka-Stenroos and Halinen (2007) classify twelve roles in four main categories: awareness, access, matching and specifying the deal. Awareness involves identifying potential partners, building awareness among suitable partners and creating a need for a specific partner. Access refers to establishing contact between partners, speeding up the initiation process and delivering marketing information. Matching includes evaluating the fit between partners, offering information about the trustworthiness of a partner and assessing the quality of a partner. Specifying the deal involves providing prospects of the relationship outcome, offering risk-reducing information and making intangible services tangible.

Both Holmen and Pedersen (2003) and Aarikka-Stenroos and Halinen (2007) emphasise the facilitating role of third actors in fostering relationship initiation. However, outside the IMP tradition, scholars have identified two main types of third actors based on the seminal work of Simmel and Wolff (1950): tertius gaudens and tertius iungens. Tertius gaudens, or 'the third who enjoys', benefits of a position between two disconnected actors by their active separation (Burt, 1992, 2000). Tertius iungens, or 'the third who connects', connects actors in a network by 
either introducing disconnected actors or facilitating new coordination between connected actors (Obstfeld, 2005). Thus, we argue that third actors may be capable of stimulating advancement and removing blocks that inhibit progress in a start up's relationship initiation. In contrast, they may also be capable of strengthening blocks against moving forward and provoking backwards conversion. However, it remains unsettled how the functions and roles of third actors drive or inhibit relationship initiation from unrecognised, recognised to considered statuses. Therefore, the first research question of this chapter is: How do the roles and functions of third actors drive or inhibit a start-up's relationship initiation?

\subsubsection{Third actors and a start-up's network embedding}

Network embeddedness is "the dependency of a firm on its links with other actors in an industrial network” (Yli-Renko \& Autio, 1998, p. 256). Embeddedness can be divided into three settings (Håkansson et al., 2009), based on the dominant type of activities connecting an organisation to a network (Yli-Renko \& Autio, 1998): the developing, producing and using setting. In the developing setting new ideas are developed; in the producing setting the developed ideas are produced; and in the using setting the ideas produced are used commercially (Håkansson et al., 2009). Start-ups are usually not yet embedded in the pre-existing networks within these settings (Oukes \& Raesfeld, 2016). Yet becoming embedded is crucial to a startup’s survival and growth (Bliemel \& Maine, 2008) because it always builds on the resource constellations, activity patterns and a web of actors in the pre-existing network (Snehota, 2011). Moreover, the value of a start-up's resources depends on its connections to the resources of others, and the outcome of its activities is interdependent with its counterparts' activities (Håkansson et al., 2009). Although it is widely recognised that becoming embedded in the pre- 
existing network is essential to start-ups (e.g. Bliemel \& Maine, 2008; Yli-Renko \& Autio, 1998), so far we have no in-depth understanding of how start-ups establish themselves therein. To shed new light onto how this process unfolds, we aim to explore the role of the third actor. To embed themselves in the developing, producing and using setting, start-ups have to initiate business relationships (Yli-Renko \& Autio, 1998). Yet the limited resources and scanning abilities of start-ups make it difficult to find competent partners with valuable resources (Kirkels \& Duysters, 2010). Furthermore, a start-up cannot always be directly involved in making new connections among relationships of its partners because of its limited network horizon (Holmen \& Pedersen, 2003). We therefore argue that third actors can stimulate a start-up's network embeddedness by facilitating the initiation of business relationships. The research of Styhre and Remneland-Wikhamn (2015) supports this argument. They investigated how a large pharmaceutical company connected small companies with public organisations, venture capital investors, universities and equipment providers to support innovation in life science. In this way, the pharmaceutical company presumably supported the embedding of the smaller companies in the developing, producing and using setting. However, their study adopted the perspective of the large pharmaceutical company, so it remains unclear how third actors stimulate network embedding from the perspective of the start-ups. As a result, the second research question of this chapter is: How do third actors facilitate the embedding of a start-up in the pre-existing developing, producing and using setting?

Business relationships are usually studied as if they were dyadic, even if they are affected by various actors and business in a larger network, (Aarikka-Stenroos, 2011). However, when a third actor participates in the initiation of a business relationship, a dyadic relationship becomes a triad. A triad exists "when relationships between three directly or indirectly associated actors 
are connected" (Vedel, Holma, \& Havila, 2016, p. 4). A triad can be open or closed: in an open triad three organisations are indirectly linked to each other through a third actor, while in a closed triad all three actors are linked directly (Vedel et al., 2016). It is often assumed that if those connected can communicate directly with each other, the importance of the third actor decreases because it is no longer necessary (Yin et al., 2012). However, Yin et al. (2012) show, inter alia, that if the organisations are dissimilar in size, the role of the third actor remains important. As start-ups often (have to) collaborate with large, established organisations, they may form a triad with the third actor who introduced them, instead of their relationship with it ceasing to exist. Although this may influence a start-up's level of network embeddedness, this has so far remained unexplored. Therefore, the third research question of this chapter is: What is the effect of the type of triad-open versus closed-that is formed with the third actor and its level of importance on the embedding of a start-up in the pre-existing network?

\subsubsection{Third actors and a start-up's venture creation}

A start-up's business development refers to the entrepreneurial process of discovering, creating and exploiting opportunities (Shane \& Venkataraman, 2000). Mainela et al. (2011) combined these phases of business development with research on technological networks and networkbased internationalisation. Based on these bodies of literature, they showed that three venture creation processes can distinguished: (1) the opportunity-centred process is focused on building a start-up’s business concept; (2) the technology-centred process involves connecting the initial ideas for new products to innovative technological solutions; and (3) the internationalisationcentred process consists of positioning a start-up in relation to actors in the international, interorganisational network (Mainela et al., 2011). However, these processes are not independent: a 
start-up’s business and technology develop simultaneously as part of the interaction with the organisations in its business network.

Raesfeld and Roos (2008) linked the three phases of a small firm's business development to the three functions of third actors defined by Holmen and Pedersen (2003). They argued that during opportunity discovery, third actors relate organisations to advance the development of the weak ties necessary for the generation of new business opportunities. During the opportunity creation, third actors join organisations to facilitate the formation of strong ties, which are crucial to the sharing of resources and new product creation. During opportunity exploitation, third actors insulate organisations to stimulate the generation of loose ties necessary to deliver products efficiently to customers. However, Holmen and Pedersen (2003) focused on the management of business relationships rather than their initiation. Although third actors may facilitate the management of relationships between connected organisations, they also introduce disconnected organisations (Obstfeld, 2005). In addition, they have only captured part of the venture creation process: the opportunity-centred process. Yet the initiation of relationships by third actors will also influence the other two venture creation processes. As a result, we argue that through initiating business relationships, third actors will affect the venture creation of a start-up. Yet an understanding of how this process unfolds is still unavailable. The fourth research question of this chapter is therefore: How does a third actor affect the venture creation of a start-up through relationship initiation?

\subsection{Methodology}

In order to achieve insights into the role of third actors in the relationship initiation of start-ups, the data collection must include information about at least three actors; the two, three or more 
relationships which link them; and how these relationship influence each other (Vedel et al., 2016). Therefore, we have used an in-depth case study to analyse the process by which the startup's key relationships are initiated. The methodology of the case has been reported in detail elsewhere (Oukes \& Raesfeld, 2016). Briefly, a retrospective analysis was done from the foundation of the start-up in 2008 until April 2013. Thereafter, the start-up was followed in realtime until the end of November 2015. The longitudinal data were collected by three methods: interviews, observations and archival data. First, nine individuals from both the start-up and its key partners were interviewed during spring 2012. These interviews were repeated with five of the interviewees one and a half years later. Interviewing the start-up as well as its partners at two different times allowed us to capture the complexities and network characteristics associated with multiplex inter-organisational relationships over time. The interviews centred around: (1) how the start-up and its artificial pancreas had developed since its foundation; (2) how its network evolved over time; and (3) how each of its relationships was initiated and coordinated, as well as how resources were exchanged between partners during the relationship. In addition to these aspects, in the second set of interviews questions were asked about how the partners interacted with each other. Despite the semi-structured nature of the interviews, there was sufficient room for the interviewee to give examples and elaborate on important situations. The selection of interviewees was based on: (1) direct interaction with the other partner(s) in the relationship, and (2) direct involvement in the development of the start-up's artificial pancreas. Secondly, the behaviour of the start-up in its relationships was actively and passively observed during the first author's stay at the company from April 2013 until November 2015. Thirdly, archival documents, such as websites, grant proposals, contracts and patents, were collected from the start-up's foundation in 2008 until November 2015. The observations and archival data were 
primarily used to help the researchers improve their understanding of data collected through the interviews. The data collection involved sensitive, confidential and political issues regarding the start-up and its partners. As a result, the individuals and organisations are given fictional names to maintain confidentiality. The transcribed interviews, field notes and archival documents were analysed in four consecutive steps. First, we described with whom, when, where and why the start-up initiated a relationship. Secondly, we looked at whether a third actor was involved in the relationship's initiation, and if so what the influence of the third actor was on the process. Thirdly, we assessed how the involvement of the third actor in the relationship initiation affected the network embedding of the start-up. Fourthly, we explored how the engagement of the third actor in the relationship initiation affected its venture creation.

\subsection{Findings}

This section describes chronologically how the relationships of the start-up were initiated and the influence of third actors on this process. In addition, we describe how the third actor subsequently affected the network embedding and the venture creation processes. Table 2.1 provides the key findings regarding the role and function of the third actors within the relationship initiation process. Table 2.2. presents the main results regarding: 1) the setting in which the start-up can embed itself through the initiation of the relationship with the specific partner, whether or not facilitated by a third actor; 2) three indicators of the level of network embedding: source, type of triad and third actor importance; and 3) the start-up's venture creation process in which the partner is primarily involved, whether or not the relationship was initiated by a third actor. Figures 2.1 to 2.3 show the network development of the start-up over time (2007-2009, 2010-2012, 2013-2015), as well as the influence of third actors on initiating 
relationships. In addition, the figures show the strength of the ties between the organisations in the start-up's network. Strong ties have a higher level of resource commitment, continue to exist over a longer period of time and have more social content at the inter-personal and interorganisational level than weak ones.

$<<<$ Insert Tables 2.1-2.2 about here $>>>$

\subsubsection{Brief description of the start-up and its product}

The start-up was established in 2008 by the inventor of the product and an angel investor. The start-up is creating a bi-hormonal artificial pancreas for the treatment of persons with Type 1 Diabetes Mellitus (T1DM). A bi-hormonal artificial pancreas (artificial pancreas below) connects an insulin/glucagon pump with a continuous glucose monitor by means of an algorithm. The algorithm calculates the correct amount of insulin (decreases blood glucose levels) or glucagon (increases blood glucose levels) to be injected based on the current blood glucose level. In turn, the pump automatically delivers that specific amount of insulin/glucagon to the body. Currently, the treatment of diabetes is a major burden to those who suffer from it. Persons with T1DM must regularly measure their blood glucose level with a finger prick and test strip, calculate their carbohydrate intake, take account of exercise, determine the required amount of insulin and inject themselves. The start-up's artificial pancreas will give them complete freedom of diet and exercise flexibility combined with fewer finger pricks and insulin injections. The expectation is that the device will considerably improve the quality of life of persons with T1DM because their disease becomes less of a burden during the day. Despite the fact that the start-up has been in existence for some time, the artificial system is not yet ready for production, let alone 
use by persons with T1DM. Consequently, the start-up can still be considered to be in the startup phase (Oukes \& Raesfeld, 2016). In order to mobilise and leverage the resources necessary to develop the artificial pancreas, such as intellectual property, distribution networks and production facilities, the start-up needed to initiate relationships with other organisations. As we explain in the remainder of this section, the start-up would not have been able to initiate all the necessary relationships without the support of third actors.

\subsubsection{Initiating the relationship with the teaching hospital}

As shown in Table 2.1, the start-up's first relationship was established with the teaching hospital in 2008. It was made aware of the existence of the Diabetology Research Group of this centre by a physician from another hospital. He contacted the start-up after he had read an article about the artificial pancreas in a magazine. The start-up anticipated that he would be able run clinical trials. It was necessary to run these trials since the efficiency, effectiveness and safety of the artificial pancreas had to be evaluated. Yet the start-up lacked the required knowledge, financial resources and facilities to run the trials itself. However, the physician was unable to run clinical trials, either, because he lacked the appropriate resources. Nevertheless, the physician referred the start-up to the head of the teaching hospital's Diabetology Research Group. The aim of this group is to conduct medical-scientific research in the field of insulin delivery and continuous glucose monitoring. Therefore, the physician identified the Diabetology Research Group as a suitable partner for the start-up. After he established the first contact between the two potential partners, the start-up was invited to give a presentation to the group's members. During the presentation, the owners of the start-up presented the results of the early tests that were run with a first prototype of the artificial pancreas. According to the head of the teaching hospital's 
Diabetology Research Group, the results were promising. This convinced him that it would be worth the effort to evaluate the start-up's idea in clinical trials. A series of meetings followed in which the Diabetology Research Group and the start-up negotiated the details of their potential relationship. In the end, they agreed that the teaching hospital would run three clinical trials in exchange for $10 \%$ of the start-up's shares. The outcomes of these trials could be used to create a second, and eventually a third, prototype of their technology: the artificial pancreas. These outcomes would not only be related to technical aspects, such as the performance of the algorithm and the product's reliability, but also involve feedback from users regarding the userfriendliness of the device (see Table 2.2). As presented in Table 2.2, after the agreement between the start-up and the teaching hospital was effected, the physician withdrew from both relationships due to lack of interest in the artificial pancreas as a research topic.

\subsubsection{Initiating the relationship with the health fund}

Shortly after the relationship with the teaching hospital was initiated, the inventor was at a beneficiary meeting of the health fund. The aim of this foundation is to cure diabetes and ensure a healthy life for diabetes patients without the daily concerns about diabetes and its complications by facilitating scientific research and providing education. At the meeting, the inventor had a conversation with the health fund's head of research. The two discovered that they had a mutual interest: improving the quality of life of diabetes patients. The mutual interest between the partners marked the start of several meetings to discuss what they might mean for each other. Thus, neither during these negotiations nor during the remainder of the relationship initiation process was a third actor involved (see Table 2.1). As the health fund was known as the largest financer of diabetes-related research, the start-up requested financial support for the 
development of a second artificial pancreas prototype. However, this request was rejected by the foundation's internal audit committee. According to its policies, every funding proposal had to be approved by this committee to justify the choice for specific projects to their accountants, beneficiaries and the wider public. Therefore, the health fund was not permitted to financially support the development of the start-up's device. In turn, the two partners were unable to reach an agreement about financial support of the artificial pancreas development. However, the health fund also appeared to support diabetes-related research with its huge network of nurses, physicians, research institutes and pharmaceutical companies. In addition, the foundation promoted new diabetes-related development among its members, such as diabetes patients and their families. As shown in Table 2.2, the health fund could consequently not only support the start-up financially, but also help them to position in the diabetes-related research network. In this way, the health fund could function as a third actor in joining the start-up with valuable partners to advance the development of their artificial pancreas.

$$
<<<\text { Insert Figure } 2.1 \text { about here }>>>
$$

\subsubsection{Initiating the relationship with the research institute}

The health fund organised meetings to connect industry and research institutes to advance new product development in the field of diabetes. Before these meetings, the foundation identifies potential partners and during the meeting it establishes contacts between the partners to build awareness among suitable partners (see Table 2.1). In 2012, the health fund organised such a meeting to discuss the latest developments regarding glucose sensors. The start-up was invited to the meeting because the existing glucose sensors were not accurate and reliable enough to 
calculate the correct amount of insulin or glucagon. The meeting was also attended by the research institute—a well-known, independent research institute—since it was developing a glucose sensor based on novel technology. It expected that this sensor would not only be more accurate, but also cheaper than existing ones (see Table 2.2). Yet the research institute needed an industry partner to determine whether there was an actual market application for its sensor and to finance its continued development. The clear complementarities between the start-up and the research institute resulted shortly after the meeting in an agreement to collaborate. They agreed to start a 'co-financing' project. In this type of project the development trajectory is divided into four phases; from scientific research to market authorisation. The start-up had to finance respectively 10, 25, 50 and 100 percent of the sensor development itself, while the remainder was funded by local government. Completing the four phases would result in a patented sensor which the start-up could exclusively licence from the research institute.

As shown in Table 2.2, the importance of the health fund did not decrease when the relationship between the start-up and the research institute was established. In contrast, the health fund became essential in resolving a conflict between the two partners. In the first year, the joint project of the start-up and the research institute made rapid progress. Then the research institute started a multi-partner research project with similar objectives. Consequently, the research institute requested the start-up to join and end the co-financing project. This, however, meant that the start-up would have to share the right to licence the patented sensor with several other companies. This was not considered beneficial by the start-up and it consequently turned down the request. This brought the research institute into a difficult position because it required the start-up's patented sensor to make progress in the multi-partner research project. As a consequence, the research institute began to obstruct the development of the sensor, so 
attempting to force the start-up to join the multi-partner project. This attempt was unsuccessful and the conflict seemed to end in an impasse. In 2014, the health fund-one of the partners in the multi-partner research project of the research institute-proposed a creative solution to resolve these issues. In essence, the foundation's proposition involved its providing the necessary financial resources to complete the development of the new sensor. In turn, the start-up would get the exclusive right to licence the patent on this sensor. Thereafter, it would join the multipartner project. This solution appears to have turned out favourably for all three parties.

\subsubsection{Initiating the relationship with the market leader}

Besides the sensor meeting for research institutes and industry, the health fund also organised a contest for innovative research projects. In this way, it aimed to deliver information to the public about the progress of research in the field of diabetes (Table 2.1). In 2012, the start-up participated and won the audience award. Winning this award attracted nationwide attention in the media for the development of its device. In this way, a department of the market leader became aware of the start-up's artificial pancreas. The market leader is a frontrunner in personalised healthcare, a global leader in cancer treatment and the leading provider of in-vitro diagnostics. In the diabetes market the firm is the leader in glucose monitoring. When the business director of the glucose monitoring department heard about the start-up, he invited it to give a presentation. During the presentation the technicians of the market leader discovered that the artificial pancreas was further developed than they had expected. Nevertheless, the development of the artificial pancreas was not yet sufficiently mature to invest in; the risk that it would fail was viewed as too high. However, the market leader wanted to keep abreast of developments at the start-up, to which end they signed a non-disclosure agreement. This 
agreement enabled the partners to share confidential knowledge and information, but restricts the counterparty from sharing it with third parties. Additionally, they signed a right of first refusal, which gives the market leader the option to enter a business transaction with the start-up before it can enter into such a transaction with a third party.

The agreements between the market leader and the start-up provided the partners the chance to build a trusting relationship and opened up opportunities for future collaboration. As a small, young company the start-up had the required flexibility to develop the artificial pancreas, but was expected to lack the resources to produce, market, sell and distribute it. In contrast, the market leader — as a large, established firm—is less well equipped to invent new diabetes devices, but it possesses the production facilities, marketing experience, sales agents and distribution network to commercialise them. Consequently, both partners saw the advantages of long-term collaboration to exploit the device developed by the start-up (see Table 2.2).

\subsubsection{Initiating the European funded project}

In 2012, the start-up not only initiated a relationship with the research institute and the market leader, it also started a European project together with the teaching hospital. When the head of the teaching hospital's Diabetology Research Group came across an interesting call for projects grants under the Seventh Framework Programme for Research and Technological Development (FP7) of the European Commission, he invited the start-up to join the application. The partners could use the grant to build a fourth prototype of the artificial pancreas and evaluate it in additional clinical trials. The teaching hospital introduced the start-up to three organisations with which it had good experience in another ongoing project. As shown in Table 2.1, this project focused on the development of another type of artificial pancreas and they were identified as 
relevant, suitable and valuable partners. Specifically, the medical university, the established industry player and the clinical research institute joined the project team. Within the European project, the medical university will examine the interactions between insulin \& glucagon administration and continuous glucose monitoring at the same site. In addition, clinical research institute will conduct and coordinate the clinical trials. Furthermore, the established industry player will be responsible for the development of a new glucagon formulation. Also, the startup's angel investor asked two organisations to join the project: the software firm and the technical university. Within the European project, the software company will be responsible for developing the presentation and reporting software for various stakeholders, such as physicians, researchers and patients. Additionally, the technical university will focus on the business development of the artificial pancreas and support the innovation network of the companies involved. Thus, the respective responsibilities of the partners were mainly focused on the technological development of the artificial pancreas. Yet with the inclusion of the technical university, the project partners also aimed to develop the business concept of the start-up to find opportunities to exploit the technology (see Table 2.2). After the project team was formed, the potential partners wrote a project proposal that suited their own interests as well as fulfilled the specifications of the European Commission. The result was a proposal that was granted more than four million Euros in funding. In September 2012, the three-year European project was launched and the partners started working on their respective responsibilities.

In 2015, the European project should have been finalised, but the development of the artificial pancreas progressed more slowly than expected. The partners therefore applied for and were granted a nine-month extension of the project. Nevertheless, the start-up had to find new sources of financing to be able to continue developing its device. To that end, the start-up wrote several 
new project applications. In almost all of these applications, the medical university was one of the project partners while the teaching hospital was involved only in some of them. As Figures 2.2 and 2.3 show, the teaching hospital first related the start-up and the medical university, while over time it joined the partners: a direct relationship between the partners emerged in which the teaching hospital was only sometimes involved.

$<<<$ Insert Figure 2.2 about here $>>>$

\subsubsection{Initiating the relationship with the regional hospital}

At the start of 2013, it appeared that the teaching hospital, responsible for conducting clinical trials within the European project, would have insufficient capacity to do so. Running the additional clinical trials was essential to demonstrate the efficiency, effectiveness and safety of the new technical features of the artificial pancreas the start-up had created, as well as give patients the opportunity to test the usability of the device's interface (see Table 2.2). A former employee of the teaching hospital, who had run the first three clinical trials, heard about this problem. At that time, she worked at the regional hospital, but was still indirectly involved with the start-up project. Finally, the teaching hospital's former employee ensured that the regional hospital would provide the capacity to run the clinical trials. As shown in Table 2.2, a close relationship was developed between the regional hospital, which provided the necessary capacity, the teaching hospital, which designed, ran and analysed the clinical trials, and the startup, which provided technical support. The emergence of this triadic relationship was facilitated by the teaching hospital which, although through a former employee, made the regional hospital and the start-up aware of each other and introduced them to each other. In response to the 
initiation of this relationship, the regional hospital wrote a press release about the development of the artificial pancreas and its role in this development at the end of 2013. Soon thereafter, the health fund also issued a press release about the start-up's development project. These press releases were picked up by some local newspapers and from there by the national press, magazines, news broadcasts and talk shows. In this way, the regional hospital and health fund spread information about the start-up that was picked up by potential partners (see Table 2.1).

\subsubsection{Initiating the relationship with the design studio}

It was during the intense media attention to the start-up's artificial pancreas in 2013 that the design studio learned about the start-up. The design studio is an institute for art, science and technology in the fields of digital media, biotechnology and cognitive sciences. Recently, the design studio had developed an application that showed the blood glucose level of diabetes patients using colours (indicating a good, neutral or bad blood glucose level) instead of the hard numbers. In this way, blood glucose level measurement was perceived to be more user-friendly. Although designers developed a good-looking design, it was not used in an actual product. So, when one of the employees saw the artificial pancreas on television, she thought that the studio's design could be applied to this device and contacted the start-up. The start-up was previously more focused on getting the artificial pancreas to work properly. However, it was also starting to consider the design of its artificial pancreas market model at that time. As the start-up lacked the required design expertise, it was interested in collaboration. Therefore, the partners started a oneyear project to implement the design studio's design in the start-up's artificial pancreas (see Table 2.2). 


\subsubsection{Initiating the relationship with the glucagon company}

In 2014, the established industry player decided to leave the European project because it had shut down its research project to develop stable, soluble glucagon. As a result of the need for stable, soluble glucagon for the bi-hormonal artificial pancreas’ commercial success, the start-up had urgently to search for a new partner. The American health foundation is a global organisation that aims to find a cure for diabetes type 1 and its complications. As shown in Table 2.1, the foundation identified the glucagon company as a suitable partner and established the first contact between the potential partners. The glucagon company is a small, American start-up founded in 2005 that is dedicated to the development of stable, soluble glucagon for the treatment of low blood sugar levels. The company was an interesting partner for the start-up as its glucagon was expected to be the first available on the market. The potential partners met a few times and held several transatlantic phone calls. In the end, they agreed it would use the glucagon of the glucagon company in the following clinical trials. In this way, the start-up did not have to use the unstable, powder glucagon currently available, while the glucagon company could test the performance of its glucagon solution in a clinical setting (see Table 2.2). However, a problem occurred: neither the glucagon company nor the start-up had the resources to finance the production of a batch of glucagon for use in the clinical trial. Previously, the start-up had had contact with an American investment company which invests in innovative research in the United States looking for a cure for Type 1 diabetes. Eventually, it appeared that the investment company did not want to invest in the development of the artificial pancreas because it was a European initiative. Yet the start-up supposed that it might be willing to support the glucagon provider, an American start-up. Indeed, the investment company was prepared to invest in the batch of glucagon. In this way, a close relationship emerged between the glucagon company, the 
investment company and the start-up. In this collaboration, the glucagon company was responsible for supplying the glucagon; the start-up delivered the artificial pancreas; and the investment company provided the necessary financial resources (see Table 2.2).

$<<<$ Insert Figure 2.3 about here $>>>$

\subsection{Discussion}

In this section, we address the research questions raised in the theory section. Figure 2.4 displays the relations between these four questions and the accompanying findings in Table 2.1 and 2.2.

$<<<$ Insert Figure 2.4 about here $>>>$

\subsubsection{How do the roles and functions of third actors drive or inhibit a start-up's relationship initiation?}

The case study shows that third actors were involved in the initiation of seven out of eight of the start-up’s business relationships. These third actors drove the initiation of its relationships from the unrecognized to the recognized and the considered statuses. For example, the health fund brought the start-up and the research institute together at a research meeting so that they would recognize their complementarities and consider collaboration. This implies that, as suggested in the literature (Holmen \& Pedersen, 2003; Kirkels \& Duysters, 2010), the start-up experienced difficulties in recognizing partners with the necessary characteristics due to its limited network horizon. In fact, it was almost exclusively dependent on the third actors to develop its portfolio of relationships. However, the third actors did not play an active role in the consideration status. 
For example, the health fund was not involved in the negotiations between the start-up and the research institute.

This lack of involvement of the third actors in the consideration status can be explained by their role in the initiation process. Table 2.1 shows that the role of the third actors in the relationship initiation process was generally either a combination of scout, awareness builder and access provider or advocate seller. The case provided no examples of third actors that specified the deal: three roles which are usually performed in the consideration status (Aarikka-Stenroos \& Halinen, 2007). This may be because Aarikka-Stenroos and Halinen (2007) investigated buyer-supplier relationships while the start-up had not yet established any relationships with suppliers or customers. The third actors in the start-up's portfolio were not 'traditional' intermediaries present in 'classical' value chains (Rose, 2012). Moreover, they were not 'traditional' organisations that provide support to young, small firms, such as incubators or venture capitalists. Therefore, the teaching hospital and health fund had neither the expertise nor the motivation to provide concrete evidence, build expectations, reduce risk and function as an evaluation assistant for the start-up and its partners. Thus, the third actors were not involved in the consideration status because they were not skilled and motivated to do so.

In addition, the third actors mainly joined potential partners, as shown in Table 2.1. The other two functions of Holmen and Pedersen (2003) were either not (insulating) or less (relating) evident. This is in line with the findings of Raesfeld and Roos (2008), who argued that in the opportunity discovering, creating and exploiting phases, the third actor would relate, join and insulate, respectively. The start-up was clearly focused on creating the artificial pancreas: it had passed beyond discovering the need for it, while it paid only limited attention to its commercialisation. As this phase requires the start-up to develop strong ties with other 
organisations to develop its device, it could be expected that 'joining' third actors would facilitate such close collaboration. Indeed, Figures 2.1 to 2.3 show that the majority of the relationships being formed, except for the relationship with the physician and the American health foundation, are strong ties.

From the discussions of these functions and roles of the third actors involved in the start-up's relationship initiation, it becomes clear that they acted with a tertius iungens orientation. The third actors acted less as an intermediary that controls inter-organisational relationships and more as a facilitator that fosters them (Styhre \& Remneland-Wikhamn, 2015). This in line with the findings of Obstfeld (2005) who showed that while the tertius gaudens is important for generating new, good ideas, the tertius iungens is crucial in developing these ideas because it requires more explicitly coordinative action. Although it is crucial for the start-up's invention that its third actors act with a tertius iungens orientation, this does not mean they actually have the motivation to do so. For example, the teaching hospital explained that they also participated in a project in which they deliberately linked up two competitors in order to identify the best potential technology.

\subsubsection{How do third actors facilitate the embedding of a start-up in the pre-existing developing, producing and using setting?}

Third actors facilitated the embedding of the start-up in the pre-existing developing, producing and using setting through the initiation of its relationships. Indeed Yli-Renko and Autio (1998) showed that in becoming embedded in a setting, the crucial step seems to be establishing initial, intense relationships with other organisations in the network. As shown in Table 2.1, there were two principal third actors - the health fund and the teaching hospital—that facilitated the 
embedding of the start-up. In total, the health fund connected the start-up three times to potential partners, while the teaching hospital introduced it to four new partners. Figures 2.1 to 2.3 reveal that tie strength affects the number of relationships that were initiated by a third partner. Whereas the teaching hospital and health fund both had a strong relationship, the physician and American health foundation had a weak tie with the start-up. This implies that start-ups can continue to benefit from the third actor role as a partner when they have a strong relationship.

Furthermore, Table 2.2 shows that both the health fund and teaching hospital were both wellembedded in one or more of the pre-existing settings. This is in line with the findings of Ahuja, Polidoro, and Mitchell (2009), who found that poorly embedded firms are more likely to form relationships with well-embedded firms because, among others, of their access to other potential partners. However, being well-embedded in one or multiple pre-existing settings was a necessary, but insufficient condition for the third actors to connect the start-up to other potential partners: they should also be motivated to do so (Aarikka-Stenroos, 2009). For example, the health fund was motivated to introduce the start-up to other partners since it was unable to provide direct financial support for the development of the artificial pancreas. Yet it believed in the device as a potential solution to diminish the burden of diabetes. This implies that a start-up can benefit from the third actor's functions and roles of well-embedded organisations as long as they are motivated to connect it to partners in its own developing, producing and using setting.

\subsubsection{What is the effect of the type of triad that is formed with the third actor and its level of importance on the embedding a start-up in the pre-existing network?}

When addressing this question, the first thing to notice is that a triad was not necessarily formed when a third actor connected the start-up to a new partner. The case shows that the third actor 
could take either an active position in the relationship initiation process or a passive one. In the former instance, a triad is (temporarily) formed between the start-up, third actor and a potential partner; that is, the third actor is directly involved in initiating the relationship. For example, the American health foundation connected the start-up and the glucagon company by contacting both organisations. In the latter instance, a triad is not formed between the three actors; that is, the third actor is only facilitating the initiation of new relationships through the generation of media attention for the start-up. For example, the regional hospital and the health fund attracted a lot of media attention to the start-up in 2013. In reaction to this, the start-up was able to initiate a relationship with the design studio. However, neither the regional hospital nor the health fund were in direct contact with this new partner. This is in contrast with the arguments of AarikkaStenroos (2011), who suggest that when a third actor participates in the initiation of a business relationship, a dyadic relationship becomes a triad. It is more in line with Vedel et al. (2016, p. 3), who argue that "it is not enough that a third actor exists for triad to form. The third actor must be associated to the other two for a triad to form." Although a third actor is not directly connected to both organisations in the second position, it still facilitates the relationship's initiation: without the media attention that the third actor generated, some of the start-up's relationships would not have been established. Therefore, the 'third actor' can still be considered a third actor, even though no triadic relationship is being formed.

A start-up is embedded in a pre-existing network when it is dependent on the resources of other organisations in that network (Wedin, 2001). These resources are bound together by activities, which form the links between the start-up and the other organisations in the network (Yli-Renko \& Autio, 1998). The case shows that the level of mutual dependency between the partners is the lowest in dyadic relationships (with a passive position of the third actor), moderate in open 
triads, and highest in closed triads. For example the start-up is greatly dependent on both organisations to successfully develop a new sensor in the closed triad with the research institute and the health fund. Therefore, the degree of network embedding is higher in a closed triadic relationship than in an open triadic and dyadic relationship, respectively. Thus, the third actor can increase the level of a start-up's embeddedness by forming a triadic relationship after initiating the relationship.

Additionally, the case shows that within a triad the importance of the third actor can either increase, decrease, or remain stable. The importance of the third actor is closely related to the dependencies between the partners: when the importance of the third actors increases the dependencies also increase, and vice versa. For example, a triadic relationship was formed between the start-up, the teaching hospital and the medical university. Over time, the start-up and the medical university wrote a joint grant application without the involvement of the teaching hospital. The partners became less dependent on the teaching hospital because it was not necessary to run clinical trials in these applications. In addition, the case shows that the strength of a tie plays a role in the importance of the third actor: in two out of three instances in which the importance of the third actor decreases, the start-up had a weak tie with the third actor. The importance of the physician and the American health foundation decreased once the initial contact with the potential partners had been made. Both these actors had a weak relationship with the start-up. Embedding is associated with the level of dependency (Wedin, 2001) as well as tie strength (Moran, 2005). Therefore, the more important a third actor becomes during the relationship with another partner, the higher the level of embeddedness. 


\subsubsection{How does a third actor affect the venture creation of a start-up through relationship initiation?}

As shown in Table 2.2, the third actors involved in the relationship initiation of the start-up stimulated its venture creation. If third actors had not established the relationships with the respective partners, the start-up would have been unable to develop its technology, nor its business and network. For example, the relationships with the research institute for the sensor and the glucagon company were initiated by the third actors to ensure that the artificial pancreas could function properly. Thus, this case shows that third actors can play an important role in a start-up’s business development through the initiation of relationships. However, the third actor is also influenced by the business development phase of the start-up (see Figure 2.4). As explained in Section 2.5.1, depending on the phase of development, a third actor usually performs a different function. The case reveals that the focus of the start-up's relationships is on the technological development of the artificial pancreas, that is the development of new technological innovations as described by Mainela et al. (2011). In contrast, the development of the business concept and the organisation of the market through its relationships have received far less attention. Only upon initiating of the relationship with the market leader did the start-up take the first steps in bringing the artificial pancreas to market (Oukes \& Raesfeld, 2016). As soon as the focus of the start-up's focus comes increasingly to lie on the commercialisation of its artificial pancreas, it can expected that the role, function and type of the third actor will change (Raesfeld \& Roos, 2008). For example, the market leader may start to insulate the start-up and the distributors or sale agencies in its network. In this way, it can facilitate the development of the weak ties necessary to deliver products efficiently to customers (Raesfeld \& Roos, 2008). 


\subsection{Conclusion}

The first conclusion that can be drawn from this case is that the start-up relied heavily on wellembedded partners with which it had a strong relationship and which functioned as a tertius iungens. This type of third actor joined the start-up with potential partners with the resources and activities necessary to advance the its product development. However, the relationships with well-embedded partners do not have to result in new ones because they do not always have the necessary skills or the motivation to perform the roles and functions of a third actor. This implies that start-ups should aim to closely connect not only with well-embedded partners, but partners with the necessary abilities and interests. However, how start-ups may select capable partners and motivate them to become involved in the relationship initiation process has so far remained under-explored. Therefore, two questions for future research are: 1) how can start-ups select well-embedded partners that have the skills to act as a third actor throughout the relationship initiation process? and 2) how can they motivate these partners to perform their role as third actors for a start-up?

Secondly, the case shows that a third actor does not necessarily have to form a triad with the start-up and a potential partner to facilitate the initiation of the relationship. This has important implications for future studies aiming to investigate the role of third actors in the relationship initiation process. To gain a complete understanding of the third actor's role in this process, both the active and passive positions of third actors should be investigated. If research only looks at third actors with a direct relationship to both sides of the new relationship, it may miss important facilitators of the relationship initiation process. Although it is not necessary for an interorganisational triad to form, the embeddedness of the start-up in the pre-existing network is higher when a triad is formed, especially when the importance of the third actor increases during 
the remainder of the relationship. Thus, a start-up can increase its embedding in the developing, producing and using setting by forming a triad with the potential partner and the third actor. The case shows that third actors are willing to form a triad when there is a close dependency between the three actors and a strong tie with the start-up and the third actor. Therefore, a start-up may stimulate the formation of a triad by: 1) attempting to increase the dependency between the three potential partners; and 2) trying to develop an intense, durable and frequent relationship with the third actor.

Thirdly, the case shows that the venture creation process is both affected by and affects the third actor's initiation of relationships. Third actors clearly facilitated the start-up's business development. However, they also performed a joining function just because the start-up was in the opportunity creation phase. This may imply that different third actors may become involved according to the stage of the start-up’s development. Accordingly, a start-up does have to select and motivate different types of partners depending on the stage of its venture creation. Therefore, it may be interesting to investigate the two questions raised above for each stage of a start-up's life cycle. This was not possible within the research reported here, because only the opportunity creation phase of the start-up was covered.

In summary, the case presented in this Chapter shows that most of the start-up's relationships are initiated by a third actor. This makes third actors not only crucial to its network embedding in the developing, using and producing setting, but also essential to its venture creation. 
Starting up in business networks Final manuscript 2016

T. Oukes \& A. von Rasefeld

\subsection{Acknowledgement}

This research was funded through FP7 grant number 305654 from the European Commission to the PCDIAB consortium, www.pcdiab.eu.

\subsection{References}

Aaboen, L., Dubois, A., \& Lind, F. (2011). Start-ups starting up: Firms looking for a network. The IMP Journal, 5(1), 42-58.

Aarikka-Stenroos, L. (2009). What stimulates business actors to promote others' business without monetary rewards? Exploratory narrative research on motivation factors. Paper presented at the 24th IMP Conference, Marseilles, France.

Aarikka-Stenroos, L. (2011). Reference Communication and Third Actors in the Initiation of Business Relationships. Dissertation, Turku School of Economics, Turku, Finland.

Aarikka-Stenroos, L., \& Halinen, A. (2007). The promoting role of third actors in initiating business relationships. Paper presented at the Proceedings of 23rd IMP Conference, Manchester, Great Britain.

Ahuja, G., Polidoro, F., Jr., \& Mitchell, W. (2009). Structural homophily or social asymmetry? The formation of alliances by poorly embedded firms Strategic Management Journal, 30(9), 941-958.

Anderson, A. R., Dodd, S. D., \& Jack, S. (2010). Network practices and entrepreneurial growth. Scandinavian Journal of Management, 26(2), 121-133.

Bliemel, M. J., \& Maine, E. M. (2008). Network embeddedness as a predictor of performance for New Technology-Based Firms. International Journal of Technoentrepreneurship, 1(3), 313-341. 
Burt, R. S. (1992). Structural holes: The social structure of competition. Cambridge: Harvard University Press.

Burt, R. S. (2000). The network structure of social capital. Research in Organizational Behavior, 22, 345-423.

Edvardsson, B., Holmlund, M., \& Strandvik, T. (2008). Initiation of business relationships in service-dominant settings. Industrial Marketing Management, 37(3), 339-350.

Håkansson, H., Ford, D., Gadde, L., Snehota, I., \& Waluszewski, A. (2009). Business in networks. Chichester: John Wiley \& Sons.

Holmen, E., \& Pedersen, A. (2003). Strategizing through analyzing and influencing the network horizon. Industrial Marketing Management, 32(5), 409-418.

Howells, J. (2006). Intermediation and the role of intermediaries in innovation. Research Policy, 35(5), 715-728.

Huggins, R., Izushi, H., Prokop, D., \& Thompson, P. (2015). Network evolution and the spatiotemporal dynamics of knowledge sourcing. Entrepreneurship and Regional Development, 27(7-8), 474-499.

Kirkels, Y., \& Duysters, G. (2010). Brokerage in SME networks. Research Policy, 39(3), 375385.

La Rocca, A., Ford, D., \& Snehota, I. (2013). Initial relationship development in new business ventures. Industrial Marketing Management, 42(7), 1025-1032.

Lamine, W., Jack, S., Fayolle, A., \& Chabaud, D. (2015). One step beyond? Towards a process view of social networks in entrepreneurship. Entrepreneurship and Regional Development, 27(7-8), 413-429. 
Starting up in business networks Final manuscript 2016

Mainela, T., Pernu, E., \& Puhakka, V. (2011). The development of a high-tech international new venture as a process of acting: A study of the lifespan of a venture in software business. Journal of Small Business and Enterprise Development, 18(3), 430-456.

Moran, P. (2005). Structural vs. relational embeddedness: Social capital and managerial performance. Strategic management journal, 26(12), 1129-1151.

Obstfeld, D. (2005). Social networks, the tertius iungens orientation, and involvement in innovation. Administrative Science Quarterly, 50(1), 100-130.

Oukes, T., \& Raesfeld, A. v. (2014). Resource interaction in relation to power: how startups strategize to cope with the challenges of mobilizing and leveraging resources in asymmetrical power relationships. Paper presented at the IMP Conference, Bordeaux, France.

Oukes, T., \& Raesfeld, A. v. (2016). A start-up in interaction with its partners. The IMP Journal. Prashantham, S., \& Birkinshaw, J. (2008). Dancing with Gorillas: How small companies can partner effectively with MNCS. California Management Review, 51(1), 6-23.

Raesfeld, A. v., \& Roos, K. (2008). How should a small company interact in its business network to sustain its exchange effectiveness? Creativity and innovation management, 17(4), 271280.

Rose, F. (2012). The economics, concept, and design of information intermediaries: A theoretic approach: Springer Science \& Business Media.

Shane, S., \& Venkataraman, S. (2000). The promise of entrepreneurship as a field of research. Academy of management review, 25(1), 217-226. 
Shipilov, A. V., Li, S. X., \& Greve, H. R. (2011). The prince and the pauper: Search and brokerage in the initiation of status-heterophilous ties. Organization Science, 22(6), $1418-1434$.

Simmel, G., \& Wolff, K. H. (1950). The sociology of Georg Simmel. Glencoe, Illinois: The Free Press.

Snehota, I. (2011). New business formation in business networks. The IMP Journal, 5(1), 1-9.

Styhre, A., \& Remneland-Wikhamn, B. (2015). Connecting life science entrepreneurs with resources and expertise: the role of iungens brokerage in life science innovation. Technology Analysis \& Strategic Management, 1-12.

Vedel, M., Holma, A.-M., \& Havila, V. (2016). Conceptualizing inter-organizational triads. Industrial Marketing Management.

Wedin, T. (2001). Networks and demand. The use of electricity in an industrial process. Dissertation, Uppsala University, Uppsala, Sweden.

Yin, X., Wu, J., \& Tsai, W. (2012). When unconnected others connect: Does degree of brokerage persist after the formation of a multipartner alliance? Organization Science, 23(6), 16821699.

Yli-Renko, H., \& Autio, E. (1998). The network embeddedness of new, technology-based firms: developing a systemic evolution model. Small Business Economics, 11(3), 253-267. 